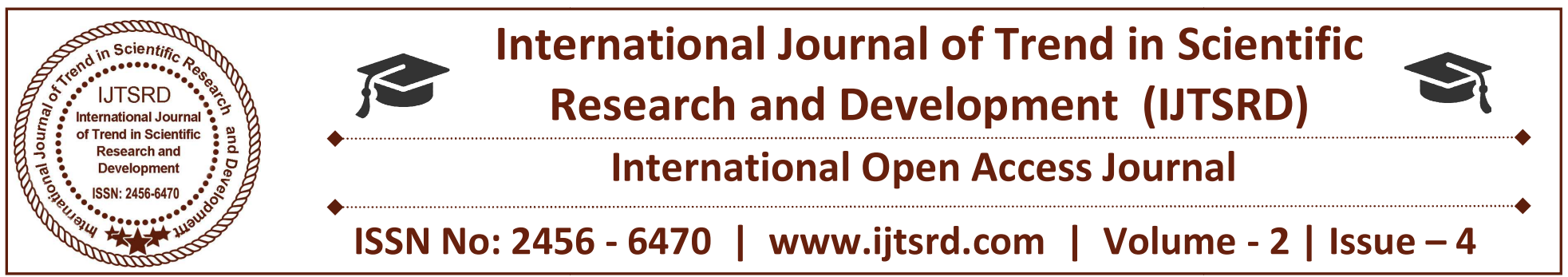

\title{
The Role of Personal Ability as A Policy of Internet Use: Exploratory Study on Small and Medium Companies in Surabaya
}

\author{
Lena Ellitan \\ Management Department, Faculty of Business \\ Widya Mandala Catholic University Surabaya, Indonesia
}

\begin{abstract}
\end{abstract}
SMEs can not avoid the development of IT even have to adopt IT. Therefore an exploratory study is required that examines the extent of IT experience in managerial and operational level employees at SMEs in Surabaya and surrounding areas, as well as the extent of their impact on the performance of individuals and SMEs as a whole. This study aims to: (1). Explore how much a user's computerized experience affects their personal ability to use the internet. (b). Explore the forms of organizational support provided by management, in enhancing personal capabilities in internal use. (3). Explore the role of computer usage experience and internet usage perception. (4). Explore the experience of computer use and perception of the ease of internet using. (5). Explore the role of organizational support to the perception of internet use. (6). Explore organizational support for ease of use of the internet. (7). Explore the role of personal capabilities that exist in employees at SMEs. (8). Explore the role of IT usage of SMEs performance. As an exploratory preliminary research, this research will be conducted on some SMEs who are willing to participate in the research. Participating SMEs will be selected according to the criteria in which they are already using information technology and also use the internet medium in their business processes. Participants in the FGD will be owners, managers, and employees (who are directly in contact with IT) in the SMEs. The scope of this study area is Surabaya and its surroundings. The findings of this study indicate that: (1). human work is assisted by the development of the technology itself in order to achieve maximum performance and improve efficiency in production activities. (2).
A person who has previous computerized experience will be easier in carrying out the production process, because it already knows the ways in operation, making it easier in doing production activities that involve a considerable amount. (3). The application in the form of utilization of computerized media as a means of design is also a means of ease of printing through digital printing, and last but not least (4). Information technology provides many benefits to the company, such as being able to lighten business activities and produce reliable, relevant, timely, complete, comprehensible and tested information in the framework of planning, controlling and management decision making.

Keywords: Personal Ability of Internet Use, Policy of Internet Use, SMEs, SMES Performance

\section{INTRODUCTION}

\section{Background}

A few years ago, the realization that IT is the key to success and corporate defense in a tight competitive environment, the potential benefits of computers as a managerial decision-making tool are not fully understood because they are not yet fully accepted by users (Swanson, 1998). The same scenario occurs in the adoption of the Internet on the organization (Tracey, 1995). The Internet is the world's connected computer network. The internet is often used to communicate, shop, research, and entertain (Timothy \& Linda, 1998). Of course, the internet is experiencing tremendous growth. Internet traffic has 
grown exponentialy, and the number of internet hosts and websites has increased tremendously.

The global economy has turned into an internet economy. Many brick-and-mortar companies are trying to turn into "clickandmortar" and dot com pioneers have grown tremendously between 1998 and 1999 but went bankrupt in late 2000 because of the economic recession. At the same time, governments around the world are trying to survive the challenges and opportunities offered by the internet. Internet prospects include a new platform of trade, a flood of publicly accessible information and a change of economic order into a new industry (Ellitan and Anatan, 2015).

In Indonesia, Malaysia, Singapore, and Thailand, developments are being made quickly to build an internet support infrastructure. China and India have also followed suit, but the country is still a third world country compared to the United States (Jack, 1997). Indonesia, like most Asian countries, is working hard to keep pace with the world economic development and its net worth especially on important issues. The list of things to do is still abundant, for example building communications networks, placing internet access equipment on citizens, creating an official framework of Internet use and most importantly promoting Internet use to Asian citizens to improve competitiveness. Undoubtedly, Indonesia $/$ for example, has understood this issue earlier than other countries. For example, the government has taken the initiative to encourage the creation of the internet world. This study aims to modify the model of technological expansion (Davis et al., 1989) by combining personal ability factors and their determinants from social cognitive theory (SCT) as an external element of the original model. SMEs can not avoid the development of IT even have to adopt IT. Therefore an exploratory study is required that examines the extent of IT experience in managerial and operational level employees at SMEs in Surabaya and surrounding areas, as well as the extent of their impact on the performance of individuals and SMEs as a whole.

\section{Research Objectives}

Based on the above research background, this study aims to: (1). Explore how much a user's computerized experience affects their personal ability to use the internet. (b). Explore the forms of organizational support provided by management, in enhancing personal capabilities in internal use. (3). Explore the role of computer usage experience and internet usage perception. (4). Explore the experience of computer use and perception of the ease of internet using. (5). Explore the role of organizational support to the perception of internet use. (6). Explore organizational support for ease of use of the internet. (7). Explore the role of personal capabilities that exist in employees at SMEs. (8). Explore the role of IT usage of SMEs performance.

\subsection{Previous Research}

A person's ability to adopt computer technology has become an important reason for encouraging him to adopt new technologies such as internet technology (Ellen et al., 1991). There are several theoretical models developed to look at individual reactions to computer technology, but Davis et al. (1989) 's technology acceptance model (TAM) have become very important (Adam et al., 1992). TAM focuses on perceptions of use and perception of technological usage as a determinant of use rather than an external factor that affects the determinant.

Furthermore, TAM explains that someone will use computer technology if they believe the results are positive. This is not related to how one expects one's expectations of their behavioral capabilities. On the other hand, social cognitive theory (SCT) believes that one's doubts about its ability to successfully adopt this behavior, beliefs about adverse outcomes will have an impact on behavior in certain situations (Bandura, 1977). Bandura (1977) indicated that personal ability, in addition to personal expectations, should be viewed in the form of adoption of new technologies. He stated, "one can believe that the action will produce a certain result, but the personal value is doubtful whether they are capable of doing so then the information will not affect their behavior".

\subsection{Social Cognition Theory and Personal Ability}

The social cognition theory (SCT) has been widely recognized and has validated individual behavioral theories based on Bandura (1977). It is based on the premise that environmental influences such as social pressure, unique situational characteristics and cognition; and other personal factors including demographic, personality and behavioral characteristics are determined reciprocally. So, one chooses the environment in which they exist when affected by that environment. At the same time, behavior in certain situations is influenced by 
circumstances or situational factors, which affect behavior. Finally, behavior influenced by personal factors and cognition will in turn affect the same factor. Bandura (1978) refers to such relationships as "triadic reciprocality" which will help explain the behavior of an individual.

While SCT has several dimensions, this study focuses on the role of cognition factors in individual behavior. Bandura (1978) raises two expectations groups as a major cognitive attack on behavior, they are: (1) expected outcomes; and (2) expectations linked to personal abilities. Results expectations can be explained by the construct use perspective developed by Davis (1989) where individuals tend to perform certain behaviors that they believe will help them to work better. Gist \& Mitchell, (1992) argue that personal ability is a belief in one's ability to mobilize motivation, the source of cognition and action required to find situational demand. SCT considers that expectations are the basis of personal behavior.

A person who does not believe in his ability will be easily broken by failure, but those who have high ability in achieving goals will strengthen their efforts when they experience a downturn and continue to succeed until they succeed. Bandura (1982) also mentions several sources of information about personal ability expectations; namely enactive mastery (personal experience) and verbal persuasion (eg, encouragement of perception and support from others). The theory of personal ability (Bandura, 1977) suggests that there are four important sources of information that one uses when forming a personal ability assessment.

In the order of strength, the first is the achievement of performance, which refers to the past's individual experiences. The second is indirect experience, which is achieved by seeing the performance of others who are successful. This is often referred to as modeling, and will help researchers to improve their performance by learning, from what they have observed (Bandura, 1978; Gist \& Mitchell, 1992). Social persuasion is the third and it refers to activities where they are led through suggestions that form the belief that they can do certain tasks such as driving a car or drawing.

Training and giving feedback on individual performance is a common form of social persuasion (Bandura \& Cervobe, 1986). The last source of information is a psychological and emotional state.
The psychological and emotional state affects the personal ability assessment of the task to be done. Through past information systems research (IS) in the context of personal ability theory, the source of information that has an important influence on the use of computer technology is personal experience and verbal persuasion.

\section{The Importance of Personal Ability}

Personal abilities are associated with beliefs and behaviors (Gist \& Mitchell, 1992). It also has a significant impact on decisions involving computer use and its adoption (Compeau \& Higgins, 1991; Ellen et al., 1991; Hill et al., 1987; Leonard \& Kraus, 1985). Someone who thinks the internet is too complex and believes that they will not be able to persuade the technology will tend to avoid and less to love it. Gist (1989) also argues that personal ability is an important motivational variable, which affects a person, his endeavors to survive and to motivate. The relationship between self-efficacy and perception of usefulness is to show the effect of personal ability on motivation and expectations of results.

Furthermore, a person who feels less capable of controlling the situation tends to maintain that sense of inadequacy and discomfort which is the result of an expected repudiation. On the other hand, a person with high self-esteem will perceive the use of this easy and useful system that is the effect of personal cultivation on the level of effort, endurance and level of learning (Bandura, 1977) and will become more resilient to change. In addition, personal ability will affect beliefs and behaviors, in particular, it will affect the use of the system indirectly through perceptions of ease of use and perception of usefulness that are two belief behaviors in TAM (Igbaria \& Livari, 1995).

\section{Determinants Of Personal Ability}

Bandura (1977, 1982, 1986) mentions several determinants of personal ability, including enactive mastery skills and verbal persuasion. Based on Igbaria and Livari (1995), these two variables are operated as previous experiences and are supportive. First: computerized experience because internet usage is one form of computer use, the computer experience (isation) is hypothesized to affect expectations positively. If someone thinks they will succeed in doing this task, then it will increase hope to master this field but if they fail it will lower the expectation to master this field as well. Bandura (1982) suggests that the experience may be influential because of 
personal characteristics. He argues that verbal persuasion positively affects personal abilities where encouragement from others will increase the expectation of becoming able. Bandura (1982) also mentions that the expectation of personal abilities growing through such verbal persuasion will be weaker than that derived from personal experience. Previous experience also relates directly to behavior and motivation. Previous experience is also believed to have an impact on behavior and motivation to what extent a person is capable of performing certain tasks.

Second: organizational support, verbal persuasion, such as support is also believed to affect beliefs, attitudes, and behavior. Someone needs a source to help them become more skilled, hopefully greater organizational support is capable of generating a higher personal self-assessment (Igbaria \& Livari, 1995). The availability of help to someone, who needs it, seems to be able to improve its ability to complete a task, in the use of the internet. Furthermore, support is one form of organizational norms; this will inevitably affect the expectations of results (perceptions of usefulness) and confidence in addition to self-ability. Davis et al. (1989) also stressed that perceptions of usefulness and perception of ease of use are influenced by management support. Trevino and Webster (1992) also suggest that organizational support is also positively related to perceived ease of use. Based on TAM, the effect of organizational support, which is an external factor, should have an indirect effect on Internet usage.

\section{Conceptual Framework}

The purpose of this study is to discuss the role of personal ability factors that influence a person to use internet technology. Moreover, personal ability plays a role as an external factor affecting one's beliefs (Gist \& Mitchell, 1992). Determinants of personal abilities such as computer experience and organizational support as mentioned above have a direct impact on behavior through their influence on beliefs, namely usability perceptions and perceptions of ease to use. Usability perceptions and perceptions of ease to use will be used as intervening variables of personal ability and determinants of Internet use.

The personal experience in which one determinant of personal ability provides the immediate and experiential basis with the perception of success in the task, the hypothesized computer experience will have an effect on the expectation of personal ability positively (Bandura, 1982, 1986). Verbal persuasion is expected to have a positive effect on personal ability, where the perception of encouragement and support from others will increase the expectation of ability. Individuals rely on opinion and support from others in shaping his thinking about his own personal abilities. It is expected that the greater the organizational support from management will result in higher personal capabilities in doing the task, in this study is the use of internet (Anatan and Ellitan, 2009b). With this understanding, the following proposition is formulated: Computerized experience is believed to develop a person's perceptions and beliefs in using technology by increasing their belief in their ability to master challenges and reduce their fears (Gist et al., 1989).

There is a statement that organizational support is also positively related to perceived ease of use (Trevino \& Webster, 1992). Organizational support is believed to be an indication of organizational norms and this will have a positive impact on the expected outcomes and confidence in personal abilities. Thus, organizational support, which is an external factor of TAM (Venkatesh, 1999) is believed to have a direct relationship with one's perception of the usefulness and ease of using the internet within the organization.

There is an argument that personal ability acts as a proximal determinant of behavior (in this case, internet use) and motivation (perception of ease of use and perception of usefulness) (Bandura 1982, 1986). Based on Gist and Mitchell (1992), personal abilities relate to expectations, where expectations impact actions. They argue that behavior-result relationships, such as business for performance, should be viewed parallel to personal abilities. This is because "expected performance results are highly dependent on the type of behavior one chooses to perform" (Gist \& Mitchell, 1992). Bandura (1982) also distinguishes personal abilities and "outcome assessments" similar to usability perceptions. Instead, Gist and Mitchell (1992) emphasize that the difficulty in performing a task will have an impact on the strength of the relationship between personal ability and performance. This suggests that perceptions of difficulty in task execution (perceived low ease of use) will mediate the relationship between personal ability and performance. It is stated that personal capability will affect ease of use and perception of usability towards internet usage. 
Based on TAM (Davis et al., 1989; Geven, 2003), perceptions of usefulness and perception of ease to use are two determinants of system use. It was found that the perception of ease to use has a significant effect on the perception of usefulness (Davis et al., 1989), the same idea supported by Adam et al. (1992) where both are important factors that influence one's decision to use the system and perceive ease of use affect the perception of usefulness. Mathieson (1991) also found that the perception of ease to use provides a variety of perceptions of usability at a certain level and the perception of ease to use and usability perceptions contribute to behavior.

Based on the theory of motivation, if a person perceives an activity as a means to achieve meaningful results. He will accept new technology. This is supported by the discovery that the use of computer systems is driven by perceptions of usefulness (Adam et al., 1992; Davis et al., 1989). Furthermore, a number of propositions related to the technology acceptance model are related to personal capabilities and the determinants have been expressed. Based on TAM, perceived usefulness is considered an important determinant of internet usage followed by perceived ease of use. Personal ability and two determinants (computerized experience and organizational support) are viewed as antecendent from perceived ease of use and usability perceptions that have an indirect effect on internet usage within an organization through two intervening variables.

\section{RESEARCH METHODS}

\section{Types of Studies and Qualitative Research Design}

This study is an exploratory and descriptive research that seeks to perform indentification and exploratory on some of the things that are formulated in the research purpose. Qualitative research method is a method to investigate objects that can not be measured with numbers or other sizes that are exact. Qualitative research can also be interpreted as descriptive research and tend to use inductive approach analysis. Qualitative research is far more subjective than quantitative research or surveys and using methods is very different from gathering information, especially individuals, in using in-depth interviews and focus groups. Unlike conventional research that is quantitative, in qualitative research, the design of the study is not predetermined. Nevertheless, the design function remains the same that is used in research to show the research design regarding how to move forward (Sugiyono, 2010).

\section{Data Collection Procedures}

As an exploratory preliminary research, this research will be conducted on some SMEs who are willing to participate in the research. Participating SMEs will be selected according to the criteria in which they are already using information technology and also use the internet medium in their business processes. Participants in the FGD will be owners, managers, and employees (who are directly in contact with IT) in the SMEs. The scope of this study area is Surabaya and its surroundings.

The study is expected to result in a document on improving personal capabilities, management should review/ one's computerization experience and organizational support, which are two factors that affect a person's belief in his ability to use the internet. Management is expected to make the right decisions such as: 1. Improved training and education programs that will improve self-ability, hence, the belief that one will develop an important experience to use the internet effectively and strengthen one's confidence in his ability to master and use it in work. 2. Management should also provide a choice of different types of Internet applications that will maximize performance. 3. Help SMEs managers promote effective functioning and acceptance of Internet technology in organizations for long periods of time, organizations need to influence positive user perceptions and beliefs related to the benefits and uses and also the usefulness of the internet in work. 4. Develop a quantitative research model on internet technology adoption in small companies. From the results of this exploratory study is expected to build the model researchers to continue with hypothesis testing research.

\section{DATA ANALYSIS}

\section{Participants}

Nineteen SMEs have participated in the research, all of which are small and medium-scale manufacturing and service companies, according to the criteria used for this study. Participating companies are selected samples and provide a complete response to the required data company profiles participating in this research are viewed in terms of business line, length of operations, assets owned, and general performance achieved over the past 3 years. These companies are 
engaged in different businesses according to 6 categories. All of them are micro, small, and medium enterprises that have been in their own business for more than three years, and only 3 relatively new companies (operating less than a year).

\section{Use of Computerized Systems, the Internet and the Reason}

There are various reasons for the use of computerized systems according to informants. The various reasons can be categorized as follows: First, by using computerized and internet will be easier for all business activities. Maybe even almost all of this business activity using computerized system and internet. Second, by using computerization and internet to facilitate the work and communication more timely. Third, ICP company in its operation using a computer as a medium to manage customer data. The data is in the process to be printed into output in the form of photos, banners, brochures, calendars, and others. Computerization is used to store data or customer and operational notes ranging from sending data to the center and gathering data from customers via online and direct sales. Fourth, the use of computerized system can help the company development faster, faster service to the customer, accommodate business competition demands and is the demand of information technology application, and the five computerized accelerated data management, both for evaluation and processing customer data.

\section{The Role of Computerized Experience in Internet Capabilities and the Reasons}

Three of the 19 companies stated that experience in computerization has no influence in the ability to use the internet this is due to: The necessity in the work of making employees learn by itself and experience and capability has become imperative for its employees. While the sixteen other informants have different reasons are: First, with a dynamic computerization to make employees and companies more responsive, Second: The more experience, the more the ability to use the internet, because to implement the internet required computer devices and systems that support all activities in accessing the network.

Third: The majority of the company's activities in carrying out its operational activities using internet facilities. (1) Enable companies in promoting to consumers, sales transactions with consumers, and seek information about things that are needed for the company (especially about competitors). (2). The use of internet in the company's operations is very high and it is realized by every employee in the company. Mostly, employees who work in the company, have previously had sufficient computerized experience, so the experience can make them more expert in utilizing and using internet facilities while working. (3) Every employee personally has a high willingness to learn and get to know the internet more. This resulted in the support provided by the company to be more easily conveyed and can be implemented by all employees well, and the fifth is the user's computerization experience affects the ability in using the internet because the use of the Internet can not be separated from the ability of people in operating it.

\section{Organizational Support in Enhancing the Ability of Computerized System and Internet}

In general the support provided is both personally and organisationally. The results of interviews with companies shows an interesting phenomenon because there are still some companies that do not provide personal or organizational support for the following reasons: (1). There is no individualized individual support to the employee, all at the employee's own initiative. Capacity building is done based on sharing the experience of one employee with another employee. (2). There is no organizational support in particular, the company is limited to preparing facilities according to the company's useful perception. Two of the 19 companies that participated in the study did not provide support either individually or organisationally. The other 17 participants in the study said they provided individual and organizational support.

\section{The Role of the Personal Ability of SMEs Employees, Work Delivered with the Ability of Computer and Internet Usage}

Various jobs facilitated by the trap of the use of computers and the internet. This depends on the business of each business field or business being involved. Some of the most commonly facilitated jobs include operational areas, marketing, human resources management and financial records. This can be seen from several cases for example: With the ability possessed by employees of Dodolan Doll plus computerized system and internet, all business activities are done easier, faster, effective, efficient, and orderly. Enhanced jobs are promotional (for using the internet), Stock Counting, bookkeeping, and 
communication (Because the raw materials used are imported from China, effective communication is needed). Kriya Leaf Workshop among others can find information from consumers faster such as (pre order), easier communication, and wider market share with the existing website so that the order increases. Pratama Buana using internet media such as email and social media: (1). Booking airline tickets on selected airlines as means of transportation to the destination. (2). Bookings of lodging (especially for 4 star and above hotel). (3). Inform about tour price list. (3). Booking the means of transportation during the tour (sometimes there are some consumers who want to rent their own vehicles, regardless of the means of transportation that has been provided). (4). Promotion and sales activities are increasingly emphasized on the use of internet facilities (in the form of social media like Facebook, Instagram, Blackberry Messenger, Line, Whatsapp). (5). Service activities, related to services that use internet facilities. This is a question and answer activity conducted between the consumer (either an individual or a small group) with the company. (6). Activity of payment of bill and receipt of payment.

\section{IT Role in Improving SMEs Performance}

IT has various roles in improving the performance of SMEs both marketing performance, financial performance, operational performance, and improve HR productivity depends on the field of business they intend to do (Anatan and Ellitan, 2009a). For example some areas of business whose performance can be improved with the existence of IT and internet usage are: (1). With the IT, then Dodolan Doll can know the current market conditions, such as prices, competitors, and what strategies should be done. This system allows Dodolan Doll to run its business to increase sales. (2). Kriya Leaf Workshop among others can find information from consumers faster such as (pre order), easier communication, and wider market share with the existing website so that the order increases. (3). Useful to speed up the work include: Data processing for evaluation materials, registration of customer data, improving employee knowledge, communication between parts, between branches and between regions. (4). Through internet media, product marketing such as promotion can be done quickly, effectively and efficiently, besides internet also help in facilitate communicate with consumer through email and whatsapp messenger, and computer that can simplify the operation.

\section{Barriers Faced by Companies in Applying Computerized and Internet Technology}

Various obstacles encountered in applying information technology, in general, these barriers include aspects of cost, employee skills, software support and provider problems. Here are some examples of obstacles that companies face: (1). Dodolan Doll is a UMKM that is even new, and to implement the computerized system and the internet it requires a fairly large cost such as the purchase of computers or laptops, gadgets, and the cost of installing wifi network devices. Another obstacle is that trained employees still make some mistakes early in use. (2). The high cost to hold computerized technology must provide computer and internet network enough. And the cost for the procurement of such technology requires a fee such as the purchase of a computer or laptop that complements the specifications and needs. Coupled with the procurement of a sufficient Internet network, does not require a fast internet connection but also must be enough to help production or marketing. (3). Many competitors are using more sophisticated machines. Although the procurement of computerized technology is quite helpful in production but if competitors have technology that is more sophisticated than our technology then we will lose competitiveness. If there is no progress then the business could go bankrupt. (4). Depend on internet connection and computer or laptop in case of error will disrupt production. If errors or disruptions to computerized technology will hamper production performance if the full production performance depends on technology. If one of them is disturbed then other performance is delayed or slow. Some companies also perceive that the computerization in its application is quite difficult, because as the owner of SMEs there are also obstacles stuttering technology or often called gaptek so even make the owner less understood in the way of operation and not quickly its use for product marketing. The cost required for a simple system is also expensive about five million rupiah. If the owner is less able to use the system as expensive then it will be useless and dormant.

\section{The Role of Technology and Information in Enhancing Long Term Competitiveness}

Associated with the role of IT in improving long-term competitiveness of informants put forward some of their opinions based on experience and obstacles. Some examples of opinions expressed by companies 
participating in this research include: First, by using technology and information, companies can analyze existing data to determine Dodolan Doll's long-term strategy to compete. Secondly, by using the internet, Dodolan Doll can find, communicate, and cooperate with suppliers from outside Indonesia (China) to supply goods at very cheap prices, and will certainly be an advantage for Dodolan Doll because it has a low cost but quite high on income. Secondly, with the application of enterprise information technology can improve operational and management performance. Technologies such as office automation, factory automation, transaction processing systems and database management systems affect the quality of the organization. Information systems in the new ICP company play a very small role in the production, distribution and sales of products or services. Increased productivity of the information process makes it slightly different in corporate productivity. Third, Information technology can help all kinds of businesses improve the efficiency and effectiveness of business processes, managerial decision-making, and teamwork, thereby strengthening competitive positions in rapidly changing markets. Information technology provides many benefits to the company, such as being able to lighten business activities and produce reliable, relevant, timely, complete, comprehensible and tested information in the framework of planning, controlling and management decision making. Almost all current organizational activity has been entered by the application and automation of information technology.

\section{CONCLUSION}

Along with the development of technology in this era of globalization, human work is assisted by the development of the technology itself in order to achieve maximum performance and improve efficiency in production activities. With the creation of this study discusses the role of each individual ability in encouraging the use of such technology in SMEs, especially in Surabaya. In carrying out its business activities SMEs using computerized system and internet in it. Computerized in terms of making the design desired by the consumer using a computer and design program such as photoshop/corel draw. Then in terms of internet use is used in searching for design for consumers as well as doing online marketing that is done via facebook and instagram.

In terms of production activities, a person who has previous computerized experience will be easier in carrying out the production process, because it already knows the ways in operation, making it easier in doing production activities that involve a considerable amount. Then in terms of marketing activities someone who has computerized experience will be more quickly and efficiently in marketing online, not just facebook, BBM, and instagram only, but can be through other platforms such as tokopedia, OLX, and many more, someone who has experience will understand more in doing the online marketing process. The use of computers and the internet in running SMEs is usually intended to design a model shirt or shirt, simplify the process of searching for clothing design, simplify the marketing, simplify the behavior that occurs after purchase (customer contact back or follow-up for questioning about customer satisfaction services provided). So in running this business requires high creativity and the ability to process graphic design, at least mastering photoshop.

The application in the form of utilization of computerized media as a means of design is also a means of ease of printing through digital printing. So the role of IT is very influential on the SMEs performance to be more competitive, it is consistent with study done by Anis, Christiananta and Ellitan (2018). In addition, screen printing can be replaced by computerization because the basic concept of screen printing is the creation of 2D without texture, and without the detailed degradation that can be done by computer easily and more satisfactory results (using support software like corel, adobe and autocad). IT can be just a supporter of business activities but can also be a determining factor of business success.

Information technology provides many benefits to the company, such as being able to lighten business activities and produce reliable, relevant, timely, complete, comprehensible and tested information in the framework of planning, controlling and management decision making (Ellitan and Anatan, 2007). So that companies can stay afloat in the era of information and able to face global market competition. With the development of information technology, almost all the current organizational activity has been entered by the application and automation of information technology(Permana, Laksmana, Ellitan, 2015). 
International Journal of Trend in Scientific Research and Development (IJTSRD) ISSN: 2456-6470

\section{REFERENCE}

1) Adams, D.A., Nelson, R.R. \& Todd, P.A. (1992). Perceived usefulness, ease of use, and usage of information technology: a replication. MIS Quarterly, 16(2), 227-247.

2) Anatan, L \& Ellitan, L. 2009a. MSDM dalam Bisnis Modern (Edisi Revisi), Alfabeta, Bandung (ISBN: 978-979-8433-26-9).

3) Anatan, L. \& Ellitan, L. 2009b. Supply Chain Management: Teori dan Aplikasi, Alfabeta Bandung (ISBN:978-979-8433-99-3).

4) Anis, BJ., Christiananta, B. Ellitan, L. 2018, The effect of entrepreneurship orientation, information technology, strategic planning to competitive advantage with business performance as intervening variables: empirical study of food processing SMEs in North Sulawesi, International. Journal of. Advanced. Research. 6(1), 236-242

5) Bandura, A. (1977). Self-efficacy: toward a unifying theory of behavioral change. Psychology Review, 84, 191-215.

6) Bandura, A. (1978). Reflection on self-efficacy. In Advances in Behavioral Research and Therapy (1), S. Rachman (ed.), Oxford, England: Pergamon Press, 237-269.

7) Bandura, A. (1982). Self-efficacy mechanism in human agency. American Psychology, 37, 122147.

8) Bandura, A. (1986). The explanatory and predictive scope of self-efficacy theory. Journal of Social Clinical Psychology, 4, 358-373.

9) Bandura, A. \& Cervone, D. (1986). Differential engagement of self reactive mechanisms governing the motivational effects of goal systems. Organizational Behavior and Human Decision Processes, 38(1), 92-113.

10) Compeau, D. \& Higgins, C. (1991). A social cognitive theory perspective on individual reactions to computing technology. In Gross, J.I., Benbasat I., DeSanctis \& Beath, C.M. (Eds.), Proceedings of the Twelfth International Conference on Information Systems, New York, 187-198.

11) Davis, F.D., Bagozzi R.P. \& Warshaw P.R. (1989). User acceptance of computer technology: a comparison of two theoretical models. Management Science, 35(8), 982-1003.

12) Ellen, P.S., Bearden, W.O. \& Sharma, S. (1991). Resistance to technological innovations: an examination of the role of self-efficacy and performance satisfaction. Academic Marketing Science, 19, 297-307.

13) Ellitan, L. \& Anatan, L. 2007. Strategi Bersaing dalam Service Driven Economy, Andi Offset, Yogyakarta (ISBN: 978-979-29-0006-4).

14) Ellitan, L. \& Anatan, L. 2015. Sistim Informasi Manajemen: Teori dan Aplikasi, Alfabeta, Bandung (ISBN: 979-8433-48-1), 3rd Edition.

15) Gist, M.E. (1989). The influence of training method on self-efficacy and idea generation among managers. Personality Psychology, 42, 787-805.

16) Gist, M.E. \& Mitchell, T. R. (1992). Self-efficacy: a theoretical analysis of its determinants and malleability. Academic Management Review, 17, 183-211.

17) Hill, T., Smith, N.D. \& Mann, M.F. (1987). Role of efficacy expectations in predicting the decision to use advanced technologies: the case of computers. Journal Of Application Psychology, 72, 307-313.

18) Igbaria, M. and Livari, J. (1995). The effects of self-efficacy on computer usage. Omega, 23(6), 587-605.

19) Jack, G. (1997). Parlez-Vous Internet. Industry Week, April, 78-82.

20) Leonard-Barton, D. \& Kraus, W.A. (1985). Implementing new technology. Harvard Business Review, 63(November-December), 102-110.

21) Mathieson, K. (1991). Predicting user intentions: comparing the technology acceptance model with the theory of planned behavior. Information System Review, 2(3), 173-191.

22) Permana, A., Laksmana, A., Ellitan, L. 2017. The Effect of Environmental Dynamism, Dynamic Managerial Capabilities, and Deliberate Organizational Learning on the SMEs Performance with Dynamic Capabilites ad Moderator Variable: A Case Study on Small SMEs in Surabaya, International Journal of Advances. Research, 5(7), 540-551. 
23) Swanson, E.B. (1988). Information system implementation. Homewood, Illinois: Irwin McGraw-Hill.

24) Soegiyono. 2010. Metode Penelitian Kuantitatif Kualitatif dan R\&D. Bandung: Penerbit Alfabeta.

25) Timothy, J. \& Linda, I. (1998). Computing Essential Annual Edition 1998. Boston: Irwin McGraw-Hill.

26) Tracey R.D. (1995). Working without a Net. Business First Of Buffalo, 11, 22.

27) Trevino, L.K. \& Webster, J. (1992). Flow in computer-mediated communication: electronic mail and voice mail evaluation and impacts. Communication Research. 19, 539-574.

28) Venkatesh, V. (1999). Creation of favorable user perceptions exploring the role of intrinsic motivation. MIS Quarterly, 23(2), 239-260. 